\title{
Insecticide susceptibility status of Phlebotomus (Paraphlebotomus) sergenti and Phlebotomus (Phlebotomus) papatasi in endemic foci of cutaneous leishmaniasis in Morocco
}

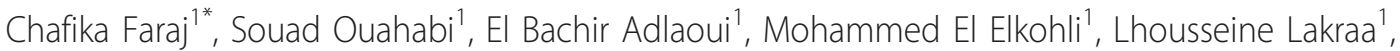
Mohammed El Rhazi ${ }^{1}$ and Btissam Ameur ${ }^{2}$

\begin{abstract}
Background: In Morocco, cutaneous leishmaniasis is transmitted by Phlebotomus sergenti and Ph. papatasi. Vector control is mainly based on environmental management but indoor residual spraying with synthetic pyrethroids is applied in many foci of Leishmania tropica. However, the levels and distribution of sandfly susceptibility to insecticides currently used has not been studied yet. Hence, this study was undertaken to establish the susceptibility status of Ph. sergenti and Ph. papatasi to lambdacyhalothrin, DDT and malathion.

Methods: The insecticide susceptibility status of Ph. sergenti and Ph. papatasi was assessed during 2011, following the standard WHO technique based on discriminating dosage. A series of twenty-five susceptibility tests were carried out on wild populations of Ph. sergenti and Ph. papatasi collected by CDC light traps from seven villages in six different provinces. Knockdown rates (KDT) were noted at $5 \mathrm{~min}$ intervals during the exposure to DDT and to lambdacyhalothrin. After one hour of exposure, sandflies were transferred to the observation tubes for 24 hours. After this period, mortality rate was calculated. Data were analyzed by Probit analysis program to determine the knockdown time 50\% and 90\% (KDT50 and KDT90) values.

Results: Study results showed that Ph.sergenti and Ph. papatasi were susceptible to all insecticides tested. Comparison of KDT values showed a clear difference between the insecticide knockdown effect in studied villages. This effect was lower in areas subject to high selective public health insecticide pressure in the framework of malaria or leishmaniasis control.

Conclusion: Phlebotomus sergenti and Ph. papatasi are susceptible to the insecticides tested in the seven studied villages but they showed a low knockdown effect in Azilal, Chichaoua and Settat. Therefore, a study of insecticide susceptibility of these vectors in other foci of leishmaniasis is recommended and the level of their susceptibility should be regularly monitored.
\end{abstract}

Keywords: Sandflies, Insecticide susceptibility, Lambdacyhalothrin, DDT, Malathion, Phlebotomus sergenti, Phlebotomus papatasi, Morocco

\footnotetext{
* Correspondence: chafikaf@gmail.com

'Laboratoire d'Entomologie Médicale, Institut National d'Hygiène, 27 Avenue

Ibn Batouta, Agdal, Rabat 10090, Morocco

Full list of author information is available at the end of the article
} 


\section{Background}

Both cutaneous (anthroponotic and zoonotic) and visceral leishmaniasis (VL) are present in Morocco. Cutaneous leishmaniasis (CL) is caused by Leishmania major Yakimoff and Schokhor, L. tropica Wright, or L. infantum Nicolle, while VL is caused by L. infantum [1]. These diseases are considered to be a serious public health concern for Morocco. Until 1999, it was mainly limited to rural areas with an hypoendemic transmission [2]. In 2001, the Moroccan Ministry of Health (MMOH) reported 2019 CL cases caused by L. major and L. tropica [3]. Since then, the disease has spread gradually from the south to the north and from rural to sub urban regions. In $2010 \mathrm{MMOH}$ reported 2263 cases caused by L. tropica and 6444 cases caused by L. major [4].

Among sandfly species involved in leishmania transmission in Morocco, Phlebotomus (Paraphlebotomus) sergenti Parrot and Ph.(Phlebotomus) papatasi Scopoli are the main vectors of Anthroponotic CL and Zoonotic CL respectively $[5,6]$. These species show large anthropophilic behaviour in peri-domestic and domestic habitats and they are widespread throughout the country in both rural and urban areas [7].

Until 2000, control measures against leishmaniasis were based only on treatment of human cases with antimonial drugs and on rodent control for ZCL [2]. Currently, they rely also on vector control measures. Indoor Residual Spraying (IRS), with synthetic pyrethroids, are applied in many Moroccan foci of L. tropica. However, these control strategies seem not to be effective to control CL throughout the country. The incidence is increasing continuously and new foci are emerging. Moreover, evaluation of chemical sandfly control points out, in some areas, the low efficiency in reducing the density of sandflies. This might be due to various factors including resistance of local sandfly populations to the insecticide in use. The pressure of insecticides used by the health sector, as well as in agricultural activities and domestic hygiene, may contribute to developing resistance in vector populations. Unfortunately, the levels and distribution of sandfly susceptibility to insecticides has not been studied in Morocco. Thus, to improve control measures against CL vectors and to provide a rational framework for choosing the suited insecticide, this study has been undertaken. It aimed to investigate the insecticide susceptibility of two Moroccan CL vectors, Ph. sergenti and Ph. Papatasi, to insecticides used in endemic areas.

\section{Methods}

\section{Study area}

This study was conducted in seven villages from six provinces in Morocco: Bouhjira (Taza) in the north-east, Lbrouj (Settat) in the center, Ait Chribou (Azilal) and Lalla Aziza (Chichaoua) on the High Atlas chain in the center-south of Morocco, Boumalne (Tinghir) in the south of the high Atlas Mountains, Bouassem (Boulemane) in the north west of the middle Atlas mountain and Ait Oublal (Boulemane) in the east of Morocco (Figure 1). These districts were selected as they are endemic for CL and have been subjected to different insecticide selection pressures.

\section{Sandfly collection}

Sandflies from the regions described were collected using CDC Light Traps during the period June-October 2011. In each village, five traps were installed in different animal's shelters from sunset to sunrise. After one hour of observation, living sandflies were selected for testing. Detailed dates of tests are given in Tables 1 and 2 .

\section{Bioassay tests}

Sandflies were exposed to three different insecticides. In each province and depending on sandfly density, tests were carried out, by priority, to lambdacyhalothrin 0.05\%, DDT 4\% then Malathion 5\%.

Insecticide susceptibility tests were carried out following WHO standard procedures using discriminating dosage [8], where field populations were exposed to a concentration of insecticide defined as diagnostic. DDT discriminating dosage, established by WHO, for the genus Phlebotomus is $4 / 1$ (exposition to $4 \%$ DDT impregnated paper for 1 hour) [9]. However, no standardized discriminating concentrations or time of exposure to lambdacyhalothrin and malathion have been given for sandflies by WHO as is the case for malaria vectors. We decided, hence, based on a literature review to consider one hour exposure to $0.05 \%$ lambdacyhalothrin and $5 \%$ malathion as a discriminating concentration [10-12].

Standard WHO testing procedures were applied to assess the insecticide resistance/susceptibility using the test-kit tubes [7]. In each test, three replicates of about 25 sandflies (not yet identified), according to the availability of the sandflies, were performed. For each batch a control test was performed using the corresponding control papers. Knockdown rates were noted at 5 min intervals during the insecticide exposure to DDT and lambdacyhalothrin. After one hour of exposure, sandflies were transferred to the observation tube and kept in appropriate conditions (25 \pm $2^{\circ} \mathrm{C}$ and $80 \% \pm 10 \%$ relative humidity) for 24 hours. Sufficient relative humidity was ensured by putting small pieces of cotton wool impregnated with distilled water on the top of the cups. After 24 hours of observation, alive and dead sandflies per cup were identified [13] and counted. Mortality rates were calculated for each target species

\section{Data analysis}

Data analysis was made using log-probit analysis software (WinDL version 2.0) developed by CIRAD-CA/MABIS 


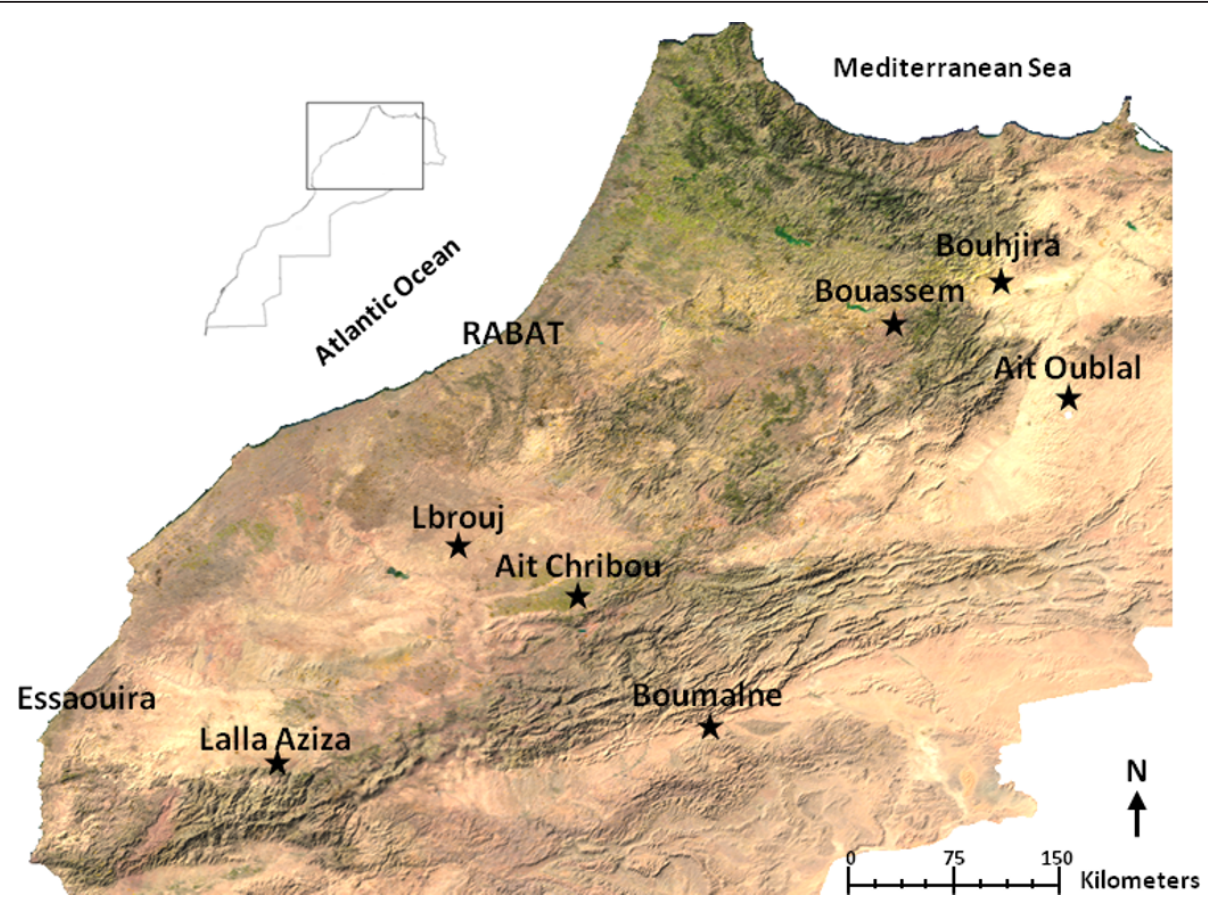

Figure 1 Map showing the study sites. * Study site.

Table 1 Insecticide susceptibility tests of wild collected Phlebotomus sergenti

\begin{tabular}{|c|c|c|c|c|c|c|c|c|c|}
\hline Province & locality & $\begin{array}{l}\text { Coor- } \\
\text { donates }\end{array}$ & Month & Insecticide & Nbre exposed & $\begin{array}{c}\text { Mortality } \\
(\%)\end{array}$ & $\begin{array}{c}\text { KDT50 mn } \\
\text { (Cl) }\end{array}$ & $\begin{array}{l}\text { KDT90 mn } \\
\text { (Cl) }\end{array}$ & Observed KDT100 mn \\
\hline \multirow[t]{3}{*}{ Azilal } & Ait chribou & $\begin{array}{l}6^{\circ} 20^{\prime} \mathrm{W} \\
32^{\circ} 11^{\prime} \mathrm{N}\end{array}$ & & Lambdacyhalothrin & 56 & 100 & $\begin{array}{c}29.3 \\
(27.2-31.4)\end{array}$ & $\begin{array}{c}64.7 \\
(57.9-74.6)\end{array}$ & $>60$ \\
\hline & & & October & DDT & 52 & 100 & $\begin{array}{c}33.8 \\
(31.5-36.2)\end{array}$ & $\begin{array}{c}71.9 \\
(63.8-84.2) \\
\end{array}$ & $>60$ \\
\hline & & & & Malathion & 51 & 100 & - & - & - \\
\hline \multirow[t]{2}{*}{ Boulmane } & Bouassam & $\begin{array}{l}4^{\circ} 33^{\prime} \mathrm{W} \\
33^{\circ} 31^{\prime} \mathrm{N}\end{array}$ & & Lambdacyhalothrin & 39 & 100 & $\begin{array}{c}12.6 \\
(8.4-16.4)\end{array}$ & $\begin{array}{c}25.6 \\
(19.5-43.9) \\
\end{array}$ & 30 \\
\hline & & & September & DDT & 51 & 100 & $\begin{array}{c}11.0 \\
(8.9-12.9) \\
\end{array}$ & $\begin{array}{c}20.6 \\
(17.4-26.6) \\
\end{array}$ & 25 \\
\hline \multirow[t]{2}{*}{ Chichaoua } & Lalla aziza & $\begin{array}{l}8^{\circ} 44^{\prime} \mathrm{W} \\
31^{\circ} 03^{\prime} \mathrm{N}\end{array}$ & & Lambdacyhalothrin & 47 & 100 & $\begin{array}{c}25.5 \\
(23.0-28.1) \\
\end{array}$ & $\begin{array}{c}72.5 \\
(62.0-89.4) \\
\end{array}$ & $>60$ \\
\hline & & & June & DDT & 40 & 100 & $\begin{array}{c}32.0 \\
(28.8-35.7) \\
\end{array}$ & $\begin{array}{c}95.7 \\
(77.7-129.0) \\
\end{array}$ & $>60$ \\
\hline \multirow[t]{2}{*}{ Settat } & Lbrouj & $\begin{array}{l}07^{\circ} 36^{\prime} \mathrm{W} \\
32^{\circ} 29^{\prime} \mathrm{N}\end{array}$ & & Lambdacyhalothrin & 44 & 100 & $\begin{array}{c}26.8 \\
(24.2-29.5) \\
\end{array}$ & $\begin{array}{c}73.0 \\
(62.4-90.3) \\
\end{array}$ & $>60$ \\
\hline & & & July & DDT & 54 & 100 & $\begin{array}{c}30.7 \\
(28.2-33.5)\end{array}$ & $\begin{array}{c}83.8 \\
(71.6-103.5)\end{array}$ & $>60$ \\
\hline \multirow[t]{2}{*}{ Taza } & Bouhajra & $\begin{array}{l}04^{\circ} 01^{\prime} \mathrm{W} \\
34^{\circ} 13^{\prime} \mathrm{N}\end{array}$ & & Lambdacyhalothrin & 43 & 100 & $\begin{array}{c}15.6 \\
(12.6-18.3) \\
\end{array}$ & $\begin{array}{c}26.3 \\
(22.0-36.1) \\
\end{array}$ & 30 \\
\hline & & & September & DDT & 41 & 100 & $\begin{array}{c}11.8 \\
(10.5-13.1) \\
\end{array}$ & $\begin{array}{c}21.5 \\
(19.2-24.8) \\
\end{array}$ & 25 \\
\hline \multirow[t]{3}{*}{ Tinghir } & Boumalne & $\begin{array}{l}6^{\circ} 00^{\prime} \mathrm{W} \\
31^{\circ} 18^{\prime} \mathrm{N}\end{array}$ & & Lambdacyhalothrin & 45 & 100 & $\begin{array}{c}14.3 \\
(11.1-17.2) \\
\end{array}$ & $\begin{array}{c}27.9 \\
(23.1-36.7) \\
\end{array}$ & 30 \\
\hline & & & July & DDT & 41 & 100 & $\begin{array}{c}12.7 \\
(11.2-14.1) \\
\end{array}$ & $\begin{array}{c}26.2 \\
(23.6-29.9) \\
\end{array}$ & 35 \\
\hline & & & & Malathion & 46 & 100 & - & - & - \\
\hline
\end{tabular}


Table 2 Insecticide susceptibility tests of wild collected Phlebotomus papatasi

\begin{tabular}{|c|c|c|c|c|c|c|c|c|c|}
\hline Province & locality & $\begin{array}{c}\text { Coor- } \\
\text { donates }\end{array}$ & Month & Insecticide & $\begin{array}{c}\text { Nbre } \\
\text { exposed }\end{array}$ & $\begin{array}{c}\text { Mortality } \\
(\%)\end{array}$ & $\begin{array}{c}\text { KDT50 mn } \\
(\mathrm{Cl}) \\
\end{array}$ & KDT90 mn (Cl) & $\begin{array}{c}\text { Observed } \\
\text { KDT100 mn }\end{array}$ \\
\hline \multirow[t]{3}{*}{ Boulmane } & Ait oublal & $\begin{array}{l}2^{\circ} 27^{\prime} \mathrm{W} \\
32^{\circ} 32^{\prime} \mathrm{N}\end{array}$ & & Lambdacyhalothrine & 54 & 100 & $\begin{array}{c}11.9 \\
(48.1-16.4)\end{array}$ & $\begin{array}{c}25.6 \\
(19.6-35.8)\end{array}$ & 30 \\
\hline & & & September & DDT & 59 & 100 & $\begin{array}{c}22.4 \\
(18.6-25.8)\end{array}$ & $\begin{array}{c}43.5 \\
(36.6-57.3)\end{array}$ & 45 \\
\hline & & & & Malathion & 58 & 100 & - & - & - \\
\hline Chichaoua & Lalla aziza & $\begin{array}{l}8^{\circ} 44^{\prime} W \\
31^{\circ} 03^{\prime} N\end{array}$ & June & Lambdacyhalothrin & 42 & 100 & $\begin{array}{c}32.4 \\
(29.1-36.3)\end{array}$ & $\begin{array}{c}102.1 \\
(82.0-139.7)\end{array}$ & $>60$ \\
\hline \multirow[t]{2}{*}{ Settat } & Ibrouj & $\begin{array}{l}07^{\circ} 36^{\prime} \mathrm{W} \\
32^{\circ} 29^{\prime} \mathrm{N}\end{array}$ & & Lambdacyhalothrine & 47 & 100 & $\begin{array}{c}33.3 \\
(30.9-35.9) \\
\end{array}$ & $\begin{array}{c}71.3 \\
62.9-84.3)\end{array}$ & $>60$ \\
\hline & & & July & DDT & 49 & 100 & $\begin{array}{c}32.9 \\
(30.6-35.4)\end{array}$ & $\begin{array}{c}71.0 \\
(62.8-83.7)\end{array}$ & $>60$ \\
\hline \multirow[t]{2}{*}{ Taza } & Bouhajra & $\begin{array}{l}04^{\circ} 01^{\prime} \mathrm{W} \\
34^{\circ} 13^{\prime} \mathrm{N}\end{array}$ & & Lambdacyhalothrin & 30 & 100 & $\begin{array}{c}14.5 \\
(13.0-15.9)\end{array}$ & $\begin{array}{c}23.4 \\
(21.0-27.3)\end{array}$ & 25 \\
\hline & & & September & DDT & 35 & 100 & $\begin{array}{c}15.3 \\
(12.0-18.3) \\
\end{array}$ & $\begin{array}{c}27.3 \\
(22.4-38.7) \\
\end{array}$ & 35 \\
\hline \multirow[t]{3}{*}{ Tinghir } & Boumalne & $\begin{array}{l}6^{\circ} 00^{\prime} \mathrm{W} \\
31^{\circ} 18^{\prime} \mathrm{N}\end{array}$ & & Lambdacyhalothrin & 51 & 100 & $\begin{array}{c}16.4 \\
(12.1-20.4)\end{array}$ & $\begin{array}{c}38.8 \\
(30.2-60.3)\end{array}$ & 40 \\
\hline & & & July & DDT & 48 & 100 & $\begin{array}{c}18.0 \\
(13.5-22.2)\end{array}$ & $\begin{array}{c}42.3 \\
(33.0-65.9)\end{array}$ & 45 \\
\hline & & & & Malathion & 31 & 100 & - & - & - \\
\hline
\end{tabular}

KDT50/KDT90: Knock down time for 50\% and 90\% of exposed sandflies with confidence intervals (Cl) at $5 \%$ level

[14]. It allows calculation of KDT50, KDT90 (Time involving respectively the knockdown of $50 \%$ and $90 \%$ of tested sandflies) and their confidence intervals.

\section{Results}

Twenty-five sets of susceptibility tests (11 for lambdacyhalothrin, 10 for DDT and 4 for malathion) of Ph. sergenti and Ph. papatasi in seven villages were carried out. Results of bioassays are presented by village in Tables 1 and 2. Ph. sergenti and $\mathrm{Ph}$. papatasi field populations tested were susceptible to lambdacyhalothrin, DDT and malathion. No specimen survived after $60 \mathrm{~min}$ exposure to these insecticides.

Nevertheless, considering the KDT values observed, the results show a difference in response among populations of both $\mathrm{Ph}$. sergenti and $\mathrm{Ph}$. papatasi to lambdacyhalothrin and DDT. Generally, KDT values for DDT were higher when compared with those for lambdacyalothrin. In the villages of Tinghir, Boulmane and Taza, lambdacyhalothrin and DDT induced a Ph. sergenti knockdown of $100 \%$ after less than 30 min of exposure. Whilst in those of Azilal, Settat and Chichaoua, the average sandfly knockdown rate at 1 hour varied between 90 and 93\%. Similarly, for Ph. papatasi, lambdacyhalothrin and DDT provided 100\% knockdown after less than $45 \mathrm{~min}$ in the villages of Boulmane, Taza and Tinghir even as, in those of Chichaoua and Settat knockdown rates varied between 85 and 93\% following one hour.

\section{Discussion}

The present paper reports the results of the first study on the insecticide susceptibility of Ph. sergenti and Ph. papatasi in Morocco.

Several studies have investigated the susceptibility of sandflies to insecticides around the world. However, the methods used in those studies were not identical i.e. insecticide concentration and time of exposure varied. Most tests have been performed on reared sandfly colonies using dose-mortality bioassays $[10,11,15]$, or Timemortality bioassays [12,16-18]. However, there are few studies that have focused on sandflies collected in the field and adopted the discriminating concentration [19-21]. We decided to carry out this study by using diagnostic dose bioassays since this method is easy, fast and requires only a small number of specimens compared to dose-mortality or time-mortality bioassays. It is, thus, more convenient for testing the susceptibility of field populations of sandflies, considering their limited density in the field.

Our results indicate that the leishmaniasis vectors Ph. sergenti and Ph. papatasi collected in this study are susceptible to lambdacyhalothrin, DDT and malathion.

These results are in line with those of several studies carried out in other countries and which concluded that, generally, sandflies are still susceptible to the majority of insecticides in use. Indeed, studies in Italy have found no evidence of DDT, pyrethroid or organophosphate resistance in Ph. perniciosus, Ph. perfiliewi or Ph. papatasi 
[18,22]. Aboul Ela et al. [10] and Fahmy et al. [17] reported the susceptibility of egyptian field populations of Ph. papatasi to DDT, dieldrine, malathion, propoxur, permethrin and deltamethrin. Further studies in Egypt confirmed the susceptibility of $\mathrm{Ph}$. langeroni, Ph. papatasi and Ph. sergenti to six insecticides (DDT, resmethrin, cyfluthrin, permethrin, bendiocarb and malathion) [11]. In Israel, susceptibility of Ph. papatasi to DDT and permethrin was reported [23]. Moreover, studies in Venezuela revealed no indication of resistance in Lutzomyia longipalpis to propoxur, malathion, deltamethrin or lambdacyhalothrin [24]. But recently, Alexander et al. [12] point out a significantly reduced susceptibility in this species to malathion, fenitrothion, lambdacyhalothrin, permethrin and deltamethrin in Brazil.

The reports on insecticide resistance in phlebotomine sandflies are few. To date, the only indicated DDT resistance has been reported in India in $\mathrm{Ph}$. papatasi [19,21,25-27] and Ph. argentipes [20,27-29]. These species were, then, found to be resistant to pyrethroids [27]. It is to be noticed that a tolerance of Ph. papatasi to DDT was signalled in Iran $[16,30]$. Considering Ph. sergenti, there have been no records of insecticide resistance until now.

In view of the KDT values observed, results of this study revealed that sandfly populations of Boulmane, Tinghir and Taza were more sensitive to lambdacyhalothrin and DDT compared with those of Azilal, Chichaoua and Settat. In the first group, either for Ph. sergenti and Ph. papatasi, KDT100 were less than $30 \mathrm{~min}$. Whereas in the second group, they were over $60 \mathrm{~min}$, MartinezTorres et al. [31] estimate that the decline in the knockdown effect can be considered as an early indicator of resistance development as it can be important before the observation of mortality reduction. This can be observed in the WHO test only when the sandfly population consists of a large proportion of homozygosity of a resistance gene. Chandre et al. [32] obtained similar results in susceptible strains of the malaria vector Anopheles gambiae, homozygous and heterozygous for the resistance gene. The observed decreased knockdown effect in the sandfly populations of Azilal, Chichaoua and Settat provinces probably resulted from DDT or pyrethroid IRS to control malaria or leishmaniasis. In Azilal, IRS with DDT to control malaria was stopped in the early 1990's. In 2010, IRS was essentially based on the use of pyrethroids (mainly alphacypermethrin) to control leishmaniasis, but only in a few villages with high incidence. Nevertheless, in Chichaoua, an insecticide spraying program to control leishmaniasis was started in 2000 and continued up till now. In Settat, the last malaria case was reported in 1995. Last IRS using DDT were carried out before this date to interrupt malaria transmission. The first outbreak of leishmaniasis was in 2007 and IRS with lambdacyhalothrin were then conducted to control transmission in this focus. However, no insecticide use in public health control programs have been reported during the last 30 years in Boulmane and Taza. In Tinghir, households have never been treated with DDT. IRS with pyrethroids to control sandflies were carried out since 2010 with alphacypermrthrin. This emphasizes that reduced knockdown in Ph. sergenti and Ph. papatasi is principally attributed to indoor insecticide spraying and their frequency of use.

\section{Conclusion}

Phlebotomus sergenti and Ph. papatasi are still susceptible to the insecticides tested in the six studied provinces in Morocco but they showed a low Knockdown effect in Azilal, Chichaoua and Settat. Thus, a study of insecticide susceptibility of these vectors in other leishmaniasis foci is suggested and the spectrum of this susceptibility should be regularly followed up.

\section{Acknowledgements}

Authors wish to extend their sincere thanks to the staff of medical delegation of Azilal, Tinghir, Taza, Boulmane, Chichaoua and Settat for their kind assistance in the field work. This investigation received financial assistance from WHO. Project ID No: EMDCD 1004953.

\section{Author details}

'Laboratoire d'Entomologie Médicale, Institut National d'Hygiène, 27 Avenue Ibn Batouta, Agdal, Rabat 10090, Morocco. ${ }^{2}$ Service de lutte Antivectorielle, Direction de l'Epidémiologie et de Lutte contre les Maladies, Agdal, Rabat 10080, Morocco

\section{Authors' contributions}

CF conceived and designed the study and drafted the manuscript. SO Carried out sandflies identification and participated in the review of the manuscript, EA carried out the data analysis and participated in the review of the manuscript. ME, LL, ME carried out the field work and the bioassay tests. BA has given financial support and participated in the review of the manuscript. All authors read and approved the final version of the manuscript.

\section{Competing interests}

The authors declare that they have no competing interests.

Received: 1 December 2011 Accepted: 19 March 2012 Published: 19 March 2012

\section{References}

1. Rhajaoui M: Les leishmanioses humaines au Maroc: une diversité nosogéographique. Pathol Biol 2009, doi:10.1016/j.patbio.2009.09.003.

2. Rioux JA: Eco-épidémiologie des leishmanioses au Maroc. Bilan de 30 ans de coopération. Direction de l'Epidémiologie et de Lutte contre les Maladies. Bull Epidemiol 1999, 37:2-10.

3. Moroccan Ministry of Public Health: Etat d'avancement des programmes de lutte contre les Maladies parasitaires Direction de l'Epidémiologie et de Lutte contre les Maladies. Rabat; 2001.

4. Moroccan Ministry of Public Health: Etat d'avancement des Programmes de Lutte contre les Maladies Parasitaires Direction de l'Epidémiologie et de Lutte contre les Maladies. Rabat; 2010.

5. Rioux JA, Guilvard E, Dereure J, Lanotte G, Denial M, Pratlong F, Serres E, Belmonte A: Infestation naturelle de Phlebotomus papatasi (Scopoli, 1786) par Leishmania major MON-25. A propos de 28 souches isolées dans un foyer du Sud Marocain. Leishmania. Taxonomie et Phylogenèse. Applications éco-épidémiologiques InstitutMéditerranéend'EtudesEpidémiologiques et Ecologiques. Montpellier; $1986,471-480$ 
6. Guilvard E, Rioux JA, Gallego M, Pratlong F, Mahjour J, Martinez-Ortega E, Dereure J, Saddiki A, Martini A: Leishmania tropica au Maroc III-Rôle de Phlebotomus sergenti. A propos de 89 isolats. Ann Parasitol Hum Comp 1991, 66(3):96-99.

7. Bailly-Choumara $H$, Abonnenc $E$, Pastre J: Contribution à l'étude des phlébotomes du Maroc (Diptera: Psychodidae). Données faunistiques et écologiques. Cah ORSTOM Sér Entomol Méd Parasitol 1971, 9:431-460.

8. World Health Organization: Instructions for determining the susceptibility or resistance of adult blackflies, sandflies and biting midges to insecticides: WHO/VBC/81.810. 1981.

9. World Health Organization: Vector resistance to pesticides. World Health Organ Tech Rep Ser 818 WHO, Geneva; 1992

10. Aboul Ela RG, Morsy TA, El Gosamy BMR, Ragheb DA: The susceptibility of the Egyptian Phlebotomus papatasi to five Insecticides. J Egypt Soc Parasitol 1993, 23(1):69-94.

11. Tetreault GE, Zayed AE, Hanafi HA, Beavers GM, Zeichner BCDJ: Susceptibility of sandflies to selected insecticides in North Africa and the Middle East. J Am Mosa Control Assoc 2001, 17(1):23-27.

12. Alexander B, Barros VC, De Souza SF, Barros SS, Teodoro LP, Soares ZR, Gontijo NF, Reithinger R: Soares Z R, Gontijo NF, Reithinger R: Susceptibility to chemical insecticides of two Brazilian populations of the visceral leishmaniasis vector Lutzomyia longipalpis (Diptera: Psychodidae). Trop Med Int Health 2009, 14(10):1272-1277.

13. Lewis DJ: Phlebotomine sandflies (Diptera. Psychodidae) of the Oriental Region. Bull Br Mus (Nat Hist) Entomol Ser 1978, 37(6):217-343.

14. Giner M, Vassal JM, Vassal C, Chiroleu F, Kouaik Z: WinDL Software version 2.0, CIRAD-CA. URBI/MABIS, Montpellier. 1999.

15. Schmidit ML, Schmidit JR: Insecticides susceptibilities of phlebotomus papatasi (Scopoli) from Egypt and the Sudan. J Med Entomol 1969, 6(1):87-90.

16. Yaghoobi-Ershadi MR, Javadian E: Susceptibility status of Phlebotomus papatasi to DDT in The most important focus of zoonotic cutaneous leishmaniasis, Isfahan Province, Iran. Iran J Public Health 1995, 24(34):11-20.

17. Fahmy AR, Khater EIM, El sawaf B, Shehata M: Insecticide susceptibility status of field populations of sandfly Phlebotomus papatasi in the Sinai peninsula, Egypt. WHO/LEISH/96.38, Geneva 1996.

18. Maroli M, Cianchi T, Bianchi $R$, Khoury C: Testing insecticide susceptibility of phlebotomus perniciosus and $P$. papatasi (Diptera: psychodidae) in Italy. Ann Ist Super Sanita 2002, 38(4):419-423.

19. Kaul SM, Wattal BL, Bhatnagar VN, Mathur KK: Preliminary observations on the susceptibility status of Phlebotomus argentipes and $P$. papatasi to DDT in two districts of North Bihar (India). J Commun Dis 1978, 10:208-211.

20. Singh R, Das RK, Sharma SK: Resistance of sandflies to DDT in Kala-azar endemic districts of Bihar, India. Bull World Health Organ 2001, 79(8):793.

21. Dinesh DS, Das ML, Picado A, Roy L, Rijal S, Singh SP, Das P, Boelaert M, Coosemans M: Insecticide Susceptibility of Phlebotomus argentipes in visceral Leishmaniasis endemic districts in India and Nepal. PLOS Negl Trop Dis 2010, 4(10):e859.

22. Lavagnino A, Ansaldi G: Susceptibility tests on Phlebotomus perniciosus and Phlebotomus perfiliewi wild populations in Sicily. Parassitologia 1991, 33(suppl):349-351.

23. Pener $\mathrm{H}$, Wilamovsky A: Base-line susceptibility of Phlebotomus papatasi to insecticides. Med Vet Entomol 1987, 1(2):147-149.

24. Mazzarri MB, Feliciangeli MD, Maroli M, Hernandez A, Bravo A: Susceptibility of Lutzomyia longipalpis (Diptera: Psychodidae) to selected insecticides in an endemic focus of visceral leishmaniasis in Venezuela. $J$ Am Mosa Control Assoc 1997, 13(4):335-341.

25. Joshi GC, Kaul SM, Wattal BL: Susceptibility of sandflies to organochlorine insecticides in Bihar (India). J Comm Dis 1979, 11:209-213.

26. Mukhopadhyay AK, Hati AK, Chakraborty S, Saxena NB: Effect of DDT on Phlebotomus sandflies in Kala-Azar endemic foci in West Bengal. J Comm Dis 1996, 28(3):171-5.

27. Amalraj DD, Sivagnaname N, Srinivasan R: Susceptibility of Phlebotomus argentipes and P. papatasi (Diptera: Psychodidae) to insecticides. J Comm Dis 1999, 3(3):177-180

28. Mukhopadhyay AK, Saxena NBL, Narasimham MV: Susceptibility of Phlebotomus argentipes to DDT in some Kala Azar endemic districts of Bihar, India. WHO/LEISH/92.31, Geneva; 1992.
29. Surendran SN, Karunaratne SH, Adams Z, Hemingway J, Hawkes NJ: Molecular and biochemical characterization of a sand fly population from Sri Lanka: evidence for insecticide resistance due to altered esterases and insensitive acetylcholinesterase. Bull Entomol Res 2005, 95(4):371-380.

30. Seyedi-Rashti MA, Yezdan-Panah H, Shah-Mahamadi H, Jedari M: Susceptibility of Phlebotomus papatasi (Diptera: Psycodidae) to DDT in some foci of cutaneous leishmaniasis in Iran. J Am Mosa Contr AssoC 1992, 8(1):99-100.

31. Martinez-Torres D, Chandre F, Williamson MS, Darriet F, Bergé JB, Devonshire AL, Guillet P, Pasteur N, Pauron D: Molecular characterization of pyrethroid knockdown resistance $(\mathrm{Kdr})$ in the major malaria vector Anopheles gambiae s.s. Insect Mol Biol 1998, 7(2):179-184.

32. Chandre F, Darriet F, Manguin S, Brengues C, Carnevale P, Guillet P: Pyrethroid cross resistance spectrum among populations of Anopheles gambiae from côte d'Ivoire. J Am Mosq Contr Ass 1998, 15(1):53-59.

doi:10.1186/1756-3305-5-51

Cite this article as: Faraj et al:: Insecticide susceptibility status of Phlebotomus (Paraphlebotomus) sergenti and Phlebotomus (Phlebotomus) papatasi in endemic foci of cutaneous leishmaniasis in Morocco. Parasites \& Vectors 2012 5:51.

\section{Submit your next manuscript to BioMed Central and take full advantage of:}

- Convenient online submission

- Thorough peer review

- No space constraints or color figure charges

- Immediate publication on acceptance

- Inclusion in PubMed, CAS, Scopus and Google Scholar

- Research which is freely available for redistribution

Submit your manuscript at www.biomedcentral.com/submit
Biomed Central 